\title{
The Federal Democratic Republic of Ethiopia: Joint Staff Advisory Note of the Poverty Reduction Strategy Paper-2003/04 Annual Progress Report
}

The attached Joint Staff Advisory Note (JSAN) of the 2003/04 Annual Progress Report on implementation of the Poverty Reduction Strategy Paper for The Federal Democratic Republic of Ethiopia, prepared jointly by the staffs of the World Bank and the IMF, was distributed with the member country's 2003/04 Annual Progress Report on Implementation of the Poverty Reduction Strategy Paper (PRSP) to the Executive Boards of the two institutions. The objective of the JSAN is to provide focused, frank, and constructive feedback to the country on progress in implementing its Poverty Reduction Strategy (PRS).

To assist the IMF in evaluating the publication policy, reader comments are invited and may be sent by e-mail to publicationpolicy@imf.org.

\author{
Copies of this report are available to the public from \\ International Monetary Fund • Publication Services \\ $70019^{\text {th }}$ Street, N.W. • Washington, D.C. 20431 \\ Telephone: (202) 623-7430 • Telefax: (202) 623-7201 \\ E-mail: publications@imf.org Internet: http://www.imf.org
}

\section{International Monetary Fund Washington, D.C.}





\title{
THE INTERNATIONAL MONETARY FUND AND \\ INTERNATIONAL DEVELOPMENT ASSOCIATION
}

THE FEDERAL DEMOCRATIC REPUBLIC OF ETHIOPIA

\section{Poverty Reduction Strategy - 2003/04 Annual Progress Report Joint Staff Advisory Note}

Prepared by the Staffs of the IMF and IDA

\author{
Approved by Carlo Cottarelli and Siddharth Tiwari (IMF) and \\ Gobind Nankani (IDA)
}

October 19, 2005

\section{OVERVIEW}

1. The Annual Progress Report (APR) documents progress with implementation of Ethiopia's Sustainable Development and Poverty Reduction Program (SDPRP) during 2003/04. The APR provides a comprehensive overview of progress in the main SDPRP pillars ${ }^{1}$, a candid overview of key challenges ahead, an updated policy matrix, and adjustments to key policies. An updated costing of the SDPRP was part of the MDG needs assessment undertaken during 2004/05 with support from the United Nations and the World Bank, and will be included in SDPRP II.

2. The APR was formally delivered in July 2005, reporting on progress from August 2003 to July 2004. This unfortunate delay weakens the information content of the APR, and limits the scope for subsequent implementation to benefit from the lessons learnt. The delayed finalization of the APR points to capacity constraints, as well as to the need to integrate reporting more firmly into the planning and budget calendar. These important process issues should be addressed in SDPRP II. One positive development has been the utilization of the SDPRP matrix as the policy matrix underpinning joint budget support, although reporting gaps remain, and data consistency with official sources needs to be strengthened. For the purpose of this JSAN, staff have utilized more recent data and policy developments as appropriate to provide an updated account.

3. As the Government is formulating Ethiopia's SDPRP II, covering the period 2005/06 to $2009 / 10$, this JSAN highlights those areas that, in the staffs' view, deserve further focus in

\footnotetext{
${ }^{1}$ The pillars comprise: (i) agricultural development-led industrialization; (ii) justice system and civil service reform; (iii) decentralization and empowerment; (iv) capacity building in the public and private sectors; and (v) food security, added in the 2002/03 APR.
} 
the SDPRP II. ${ }^{2}$ The priorities include the development of: (i) key structural reforms required to raise growth; (ii) measures to accelerate private sector and financial sector development; (iii) alternative macroeconomic scenarios within a realistic medium-term framework, supplemented by analytical work on a risk management strategy; and (iv) measures to strengthen administrative capacity, including a more detailed vision for deepening fiscal decentralization. Building on past consultative processes with civil society and the donor community, and gains in Ethiopia's democratic transition, SDPRP II should include a more systematic approach to participatory and consultative processes underpinning implementation of the SDPRP, particularly with regard to the regions, private sector and civil society.

\section{Progress With Implementation of the Poverty Reduction Strategy}

\section{A. Macroeconomic Policies}

4. The APR provides a comprehensive review of macroeconomic developments in $\mathbf{2 0 0 3 / 0 4}$. Staff acknowledge the strong real GDP growth and a decline in inflation, owing to the recovery of crop production following the drought of 2001/02-2002/03. The APR reports the government's real GDP growth target of 7 percent for 2004/05, although without elaborating on key macroeconomic policies and reforms underpinning the target. As the government projects high GDP growth rates over the medium term - against a background of a 4.0 percent average over the past decade and low estimates of potential output growth - the APR would have benefited from an elaboration of the critical reforms required to raise real GDP growth to sustainable levels. Also, in light of Ethiopia's vulnerability to rainfall variations, the risks and policies to support stronger growth should be discussed in SDPRP II and in future progress reports, and presented using alternative macroeconomic scenarios. Preliminary data suggest that growth in 2004/05 may be between 7 and 9 percent.

5. The APR appropriately discusses the difficulties encountered during 2003/04 in budget execution on account of the unpredictability of external aid flows. While the report notes that steps are being taken to improve aid harmonization, it does not identify these measures, e.g. the proposed aid platform approach to harmonize projected aid disbursements, and further steps needed on the part of donors. The need for further elaboration of this issue in SDPRP II is particularly important given the potential for a significant scaling up of external assistance to Ethiopia to support achievement of the MDGs.

\section{Staff welcome the Government's commitment to prudent macroeconomic}

policies. However, the authorities should make every effort to achieve maximum donor participation in financing the key programs under the SDPRP. In 2003/04, and according to

${ }^{2}$ The priority areas include issues already identified in the Joint Staff Assessment (JSA) of the 2002/03 APR (IMF Country Report 04/59) as requiring further clarification, which were not fully addressed in this APR. 
preliminary information for 2004/05, recourse to domestic financing of the budget deficit was almost double the amount that had been projected. Excessive domestic bank financing of the budget deficit could crowd-out the private sector, increase pressure on reserve and inflation targets, and, given the already high levels of domestic debt, increase vulnerability to macroeconomic shocks. Public infrastructure investment recently increased substantially despite the lack of sound cost-benefit analysis. The SDPRP II would benefit from a more formal technical scrutiny of large investment plans, including capacity constraints; the implications of public investment on future recurrent spending; further analysis of macroeconomic risks and options to manage these risks; and alternative financing strategies. To the extent relevant to the implementation of poverty reducing programs, the investment plans of large public enterprises should also be included in SDPRP II.

\section{Staff welcome continued efforts over a broad front to improve public} expenditure management. However, a number of important outstanding issues should be addressed in SDPRP II, including formulating action plans to: (i) make progress with the implementation of performance budgeting; (ii) strengthen the Expenditure Management and Control Program (EMCP) office; (iii) address weak capacity at federal, regional and district offices; (iv) achieve more timely reporting and public dissemination of fiscal data essential for proper fiscal monitoring and budget planning; and (v) reduce the continuing backlog of audited fiscal accounts.

8. The most recent debt sustainability analysis reveals remaining concern about Ethiopia's public debt sustainability, even following debt relief received under the Enhanced HIPC Initiative (including topping-up relief). While this assessment will be affected by the recently announced Multilateral Debt Cancellation Initiative, it will be important that the authorities take the opportunity of SDPRP II to discuss their strategy for consolidating the gains achieved under the Enhanced HIPC Initiative, and for ensuring longterm debt sustainability. In this context, the priority should be to develop a comprehensive public debt management strategy for the public sector as a whole, including debt targets, and the appropriate institutions to ensure its implementation.

\section{B. Poverty Reduction}

9. Staff note positive developments in non-monetary poverty reduction. The strong pro-poor emphasis of government expenditure is paying off in terms of improvements in education and provision of health services, as confirmed by the Central Statistical Authority's (CSA) 2004/05 Welfare Monitoring Survey (WMS) - made available only in July 2005.

10. Growth recovery in $2003 / 04$, particularly food production, might have helped a recovery of household welfare (to be confirmed when consumption figures become available), although the longer term trend on monetary poverty is not yet clear. The WMS (January 2005) suggests the 2002/03 drought shock might have been difficult to overcome (with less than a third of households feeling better off after a year). Staff recommend that SDPRP II includes an analysis of longer term trends in monetary and non- 
monetary poverty, and the evolution of the household vulnerability, particularly taking into account developments in food prices.

\section{Sectoral Policies}

11. Overall progress on sectoral performance has been good, especially with respect to service delivery, although key constraints to growth remain to be addressed as part of SDPRP II. This section reviews progress in key sectors, namely rural, safety net, private sector, financial sector, institutional reforms and capacity building, and education and health.

\section{Agricultural performance has been strong, though concerns remain about long} term prospects. Production increases in 2003-05 mostly reflect land expansion, favorable weather conditions, and expansion of rural services. Neither per capita food production nor land productivity has increased, and labor productivity has declined. With the institutional reorganization of the Ministry of Agriculture and Rural Development, there has been some progress with policy implementation, though concerns remain. Delivery systems have limited impact, are not readily responsive to demand, and over-emphasize delivery of inputs over advice. The new marketing strategy does not adequately address competition and private sector investment, especially in input markets, and is overly reliant on the promotion of cooperatives. The useful innovations in the land tenure regime should be strengthened through expediting land certification and clarifying compensation mechanisms and transferability. Also, to achieve a more balanced approach to agricultural development the authorities should: (i) strengthen agriculture input markets (seeds and fertilizers), making them more competitive with greater private sector involvement; and reduce land degradation through investment in soil conservation and soil management; (ii) enhance knowledge on the use of federal funds for agriculture; (iii) complete the agriculture services capacity building project; and (iv) strengthen rural finance.

\section{The shift from food-aid to cash is a welcome innovation; however the need to} fully implement key measures for mitigating humanitarian risks remains. The system supports labor intensive projects benefiting the poor (irrigation, water harvesting, small-scale agriculture and commerce, and voluntary resettlement). Mitigating risks to the poor will require stronger links between the Safety Net Program (SNP) and the emergency program, improved training on program procedures, appropriate targeting, and an expeditious feedback from implementation to execution of plans. Woredas (districts) should improve their capacity (financial management, procurement logistics, etc.) and enhance their support for vulnerable groups unable to undertake public works.

\section{Staff welcome positive developments with respect to the private sector, and} encourage the authorities to accelerate the pace of reform. The performance of the private sector, especially the growth in value added in private industry, construction and floriculture sectors was encouraging. The business climate benefited from expansion of telecommunications and power sector infrastructure, simplification of registration and licensing procedures, improvements in customs clearance, better access to urban land, and the enactment of the Trade Practices Proclamation. Nevertheless, the contribution of the 
private sector to the economy remains limited; e.g. public enterprises on average still account for more than half of industrial output. In the staff's view, accelerating the pace of reform will require: (i) strengthening the implementation capacity of the Privatization and Public Enterprises Supervisory Authority (PPESA) and the Competition Commission (CC); (ii) implementing effectively the broader public sector reform program supported by Public Service Capacity Building Program (PSCAP), including legal and judicial reform, (iii) executing market-based privatization transactions to reach the targets in the Privatization Action Plan; and (iv) strengthening services for private business development. The SDPRP II should build on the findings of the Diagnostic Trade Integration Study to address major impediments to private sector development, and proceed more assertively with trade liberalization and integration in the global economy including through the WTO accession process.

\section{Staff welcome progress in invigorating the financial sector, although the pace} and scope of reforms remain slow. The market share of private banks has increased, the share of nonperforming loans in the public banking system been reduced and banks' credit to the private sector increased. However, the financial sector remains shallow and undiversified, with limited competition and innovation, poor regulation and supervision, inadequate financial sector infrastructure, and lack of capacity and professional skills. Staff support the steps the government is taking to (i) improve the performance of the three public banks; (ii) implement the National Bank of Ethiopia's (NBE) Strategic Plan; and (iii) complete the study on excess liquidity in the banking system. However, the staff urge the authorities to elaborate in the SDPRP II a broader strategy for the continued development of the financial sector to enhance its role in supporting economic growth. This strategy should address a number of challenges including: (i) modernizing the payments system, upgrading the credit information bureau, establishing infrastructure for capital market development, and setting up an asset registry; (ii) enhancing competition in the banking system; (iii) developing new financial products such as housing and leasing finance, debt and equity instruments, etc; and (iv) enhancing the professional skills and capacity of financial sector practitioners, regulators and supervisors. In addition, sustained efforts are needed to ensure all banks are in compliance with existing provisioning directives.

\section{Staff welcome progress in implementing key aspects of the government's} institutional transformation and capacity building program, though constraints remain. Notable achievements include: the woreda decentralization, the fiscal decentralization strategy, legislative and judicial strengthening, modernization of law enforcement, the rollout of performance management across the civil service, and the improvements in public sector procurement and financial management. However, the staff urge the authorities to proceed cautiously with proposals to further devolve the tax administration in order not to weaken revenue efficiency. Remaining constraints pertain to: (i) public sector brain drain due to poor wages; (ii) erratic resource flows and poor incentives to perform in the intergovernmental fiscal system; and (iii) lack of clarity in the roles of the political leadership and technical staff across the public administration. 
17. The APR records some notable achievements in the delivery of key social services, though new concerns have emerged; particularly as service delivery is decentralized. In the education sector, while enrollment increased significantly, indicators of instructional quality have declined, sub-sectoral budget allocations are unbalanced in favor of tertiary education; and capacity constraints, particularly at the woreda level, will need to be overcome to ensure the sustainability of sectoral expansion plans. For health services, while the Health Extension Services training program has achieved high targets, progress has stalled in some areas. This seems partly due to the fragmentation and unpredictability of external assistance, low capacity for procurement of large quantities of health commodities and equipment, and uncertain resource allocation to woreda health budgets. Although there appears to have been welcome progress in combating HIV/AIDS, more information is needed on key indicators to further assess the extent of progress in this area.

\section{Monitoring AND Evaluation}

\section{As recommended by the last JSA, the M\&E Action Plan has been finalized -} though implementation remains a priority for SDPRP II. Remaining challenges include: (i) collection of high quality policy outcomes indicators; (ii) formal poverty impact analysis of policies and programs; (iii) closer collaboration between data producers and users (both within government and civil society), and better exploitation of data; (iv) integration of sectoral and local monitoring with SDPRP monitoring; (v) improving the timeliness of M\&E reporting; and (vi) strengthened capacity in the Welfare Monitoring Unit. To increase quality and facilitate reporting, staff suggest that the new policy matrix should focus on a limited number of high quality indicators for which both baselines and targets have been set.

\section{Conclusion}

19. Staff commend the government for preparing a much improved APR relative to the first report. This APR provides a comprehensive overview of progress with implementation of the SDPRP, along with remaining policy challenges over a broad range of issues to achieve the Government's poverty reduction targets. In the future, however, it will be important to ground the APR more firmly in the established planning and budget processes, to ensure timeliness and policy links, and consistency between results reported in the APR and other official data sources.

20. Looking ahead, the staff will actively support the government's current efforts to finalize the SDPRP II. The key outstanding issues were flagged in paragraph 3 . The overriding challenge is to raise economic growth to sustainable levels to reach the MDGs, founded on implementing critical reforms and identifying appropriate financing strategies. The Fund and Bank staffs, together with other development partners, stand ready to assist the Government in addressing this formidable task. 